\title{
PODE O DEFLACIONISMO NEGAR O PRINCÍPIO DE BIVALÊNCIA?
}

Teresa Marques

Centro de Filosofia da Universidade de Lisboa e LOGOS - Universidade de Barcelona ${ }^{1}$

\section{Introdução ao problema}

Aristóteles, na Metafísica, disse o seguinte:

"Mas também não é possível que haja algo intermédio entre contraditórios, mas é necessário, ou afirmar, ou negar um [predicado] qualquer de um [sujeito]. Isto é evidente, em primeiro lugar, se definirmos o que é o verdadeiro e o falso. Com efeito, dizer que o que é não é, ou que o que não é é, é falso; e dizer que o que é é, e que o que não é não é, é verdadeiro, de tal maneira que também aquele que diz que [algo] é ou que não [é], diz o verdadeiro ou o falso." (Metafísica IV, 7, $\left.1011^{\mathrm{b}} 23-28\right)$

Aristóteles argumenta aqui que, dada uma concepção natural da verdade e da falsidade, sempre que dizemos que alguma coisa é o caso, dizemos alguma coisa verdadeira ou falsa. Se assim é, não pode haver "algo intermédio entre contraditórios", e o princípio de bivalência é correcto.

$\mathrm{O}$ deflacionismo quanto à verdade é uma das teorias da verdade mais populares nas últimas décadas. De acordo com o deflacionismo, a verda-

\footnotetext{
${ }^{1}$ Agradeço a ajuda de Maria José Figueiredo pela tradução da passagem de Aristóteles citada. Agradeço também a João Branquinho, Paul Egré, Manuel García-Carpintero, Michael Glanzberg, Patrick Greenough, John Hawthorne, Peter Ludlow, Sebastiano Moruzzi, Robert Stainton, Peter Sullivan, Célia Teixeira e Elia Zardini a ajuda, críticas e sugestões. O trabalho aqui apresentado foi possível graças ao apoio financeiro da bolsa SFRH/BPD/16678/2004 (FCT) e dos projectos Conteúdo, POCTLFIL/55562/2004 (FCT), do Centro de Filosofia da Universidade de Lisboa e Ontological Dependence, HUM2004-05609-C02-01 (DGI, Ministério Espanhol da Investigação e Educação) do grupo LOGOS da Universidade de Barcelona.
} 
de não é uma propriedade substancial. O essencial que há a dizer sobre ela está captado em certos esquemas para a verdade que são semelhantes ao dictum aristotélico sobre a verdade. Pode, então, um deflacionista aceitar que há "algo intermédio entre contraditórios", isto é, que há contra-exemplos ao princípio de bivalência?

Muitas pessoas consideram a existência de certos casos problemáticos uma boa motivação para negar o princípio de bivalência, e entre essas pessoas encontram-se alguns deflacionistas. O deflacionista deve defender que todos os casos de esquemas para a verdade são correctos e essenciais à compreensão do que a verdade é. Mas o deflacionista depara com um grave problema quando é confrontado com a possibilidade de contra-exemplos ao princípio de bivalência. O princípio de bivalência diz que, se $\mathrm{X}$ é um portador de valores de verdade, $\mathrm{X}$ é ou verdadeiro ou falso. $\mathrm{O}$ problema do deflacionista é então tornar a suposição de que há contra-exemplos à bivalência compatível com a correcção do esquema para a verdade. Há, em particular, um argumento simples que demonstra que a suposição da existência de contra-exemplos à bivalência é absurda, se o esquema para a verdade for correcto.

Este não é o único problema com que se confrontam os esquemas para a verdade. É sabido que casos de paradoxos como o do mentiroso geram problemas a qualquer teoria, e o deflacionismo não é excepção. Outro problema normalmente pouco mencionado é o de a possibilidade de existirem contra-exemplos ao princípio de bivalência (chamemos-lhes falhas, que podem ser ou nenhum valor de verdade ou outro valor entre verdadeiro e falso) poder, por si só, indicar que o esquema da verdade não é correcto. Para salvaguardar os esquemas, pode apelar-se àquilo a que chamo o requisito de prioridade, de acordo com o qual o estatuto/valor de verdade de uma frase 'é verdade que $P$ ', que incllui o predicado de verdade, deve ser o mesmo que o estatuto/valor de verdade de uma frase anterior ' $P$ ', que não contém um predicado de verdade.

Vou argumentar, contudo, que as tentativas que têm sido feitas para tornar a suposição da existência de contra-exemplos ao princípio de bivalência compatível com os esquemas para a verdade fracassam. Essas tentativas têm normalmente dois momentos: em primeiro lugar, procuram lidar com a forma como podemos rejeitar que um certo item é bivalente sem cairmos em auto-contradição, e em segundo lugar, procuram explicar como, apesar de haver falhas, os esquemas para a verdade e falsidade continuam a ser correctos. A rejeição de que uma frase é bivalente pode ser feita, ou revendo o sentido de negação empregue, ou pelo quietismo, justificando a abstenção de afirmar, de uma forma ou de outra, que uma frase tem um valor de verdade. Um dos problemas destas propostas é encontrar uma forma que não seja ad hoc de justificar, quer um diferente uso para a negação, quer o quietismo. 
Qualquer destas propostas pode exigir que a verdade e a falsidade sejam, de alguma forma, tratadas como predicados parcialmente definidos (haverá casos para os quais a sua aplicação não está definida) $e$ que o requisito de prioridade se aplique. Contudo, não podemos estipular simplesmente que a verdade e a falsidade são predicados parcialmente definidos. A objecção fundamental que vou levantar é a de que o requisito de prioridade é usado para salvaguardar os esquemas (T) e (F), mas ao mesmo tempo a plausibilidade do requisito de prioridade depende da plausibilidade de (T) e (F). Ora, enquanto que os esquemas parecem plausíveis com casos 'normais', não é de todo claro como devem ser tratados em casos problemáticos. Portanto, o requisito de prioridade de nada serve na defesa dos esquemas. Pelo contrário, argumentarei que os casos de falhas, a existirem, falsificam os esquemas $(\mathrm{T})$ e (F), e que, portanto, nem os predicados de verdade e falsidade têm de ser parcialmente definidos, nem a noção de negação tem de ser revista. Consequentemente, o que deve ser avaliado é se os alegados casos de falhas realmente motivam uma concepção de verdade que não é essencialmente captada pelo esquema (T). Mas este é um problema que ultrapassa o âmbito deste ensaio.

Em conclusão, das duas uma, ou o deflacionismo é inadequado enquanto teoria sobre a verdade, ou não existem contra-exemplos à bivalência e o princípio não pode ser coerentemente negado. Concluo salientando que não é só o deflacionismo que se confronta com este dilema. Qualquer pessoa que defenda que alguma versão dos esquemas para a verdade e falsidade é correcta confronta-se com o mesmo tipo de dificuldade, mesmo que não pense, como o deflacionista, que os esquemas dizem 'tudo o que há a dizer sobre a verdade'.

\section{Deflacionismo e bivalência}

\subsection{O que é o deflacionismo e o que o motiva?}

Existem várias versões do deflacionismo. Entre os seus defensores encontram-se por exemplo Hartry Field, Paul Horwich e Scott Soames. As diferenças entre as propostas de cada um destes autores dizem respeito aos detalhes da formulação da teoria, e à escolha dos portadores básicos de valores de verdade. Assim, enquanto que, por exemplo, Field sugere que avaliemos as frases ou as elocuções de frases quanto a valores de verdade, Paul Horwich e Scott Soames defendem que é a proposição expressa na elocução de uma frase que é primariamente avaliável como verdadeira ou falsa.

Uma ideia comum às várias versões do deflacionismo é a de que a verdade não é uma propriedade substancial, e que portanto é um erro 
tentar investigar a sua natureza subjacente. A tese central do deflacionismo é a de que o significado do predicado de verdade é esgotado (ou é definido implicitamente) em casos particulares de certos esquemas, os quais pretendem captar a noção de verdade tal como ela foi elucidada por Aristóteles. Se a verdade for predicada de frases, então temos o esquema:

$$
\text { (T) ' } P \text { ' é verdade se, e só se, } P \text {. }
$$

Uma formulação alternativa é o esquema de equivalência que predica a verdade de proposições, identificadas como aqueles itens que são expressos por certos usos de frases declarativas, e referidos com expressões nominais da forma 'que $P$ '

$$
\text { (T*) É verdade que } P \text { se, e só se, } P \text {. }
$$

É ainda possível formular esquemas em que a verdade é predicada de elocuções que dizem que algo é o caso:

(T**) Se $e$ diz que $P$, então $e$ é verdadeira se, e só se, $P$.

A falsidade é normalmente introduzida desta forma:

(F) ' $P$ ' é falsa se, e só se, não (é o caso que) $P .^{2}$

Os deflacionistas defendem a sua teoria com argumentos e comentários de teor diverso. Segundo Horwich, por exemplo, o predicado 'verdade' existe para satisfazer uma necessidade lógica, a qual se manifesta na correcção de inferências tais como:

(P1) Eu penso que hoje está calor.

(P2) É verdade que hoje está calor.

(C1) Aquilo que eu penso é verdade.

(C2) Hoje está calor.

Segundo Horwich 1998, pp. 2-3, as proposições relativas à verdade derivam a sua utilidade da correcção de inferências como esta. A verdade desempenha este papel inferencial porque, para qualquer frase declarativa " $P$ ", obtemos uma expressão nominal "que $P$ " à qual o predicado "é verdade" pode ser acrescentado. Isto é, "é verdade" é um nominalizador, mas é também um denominalizador, pois obtemos a frase " $P$ " a partir de

2 Obviamente, poderíamos formular esquemas correspondentes para a falsidade com base em ( $\left.\mathrm{T}^{*}\right)$ ou em ( $\left.\mathrm{T}^{* *}\right)$. A falsidade pode ser introduzida, ou como não-verdade, ou como a verdade da negação. Em qualquer dos casos, obter-se-á sempre a equivalência entre 'é falso que $P$ ' e 'não $P$ '(ou 'não é o caso que $P$ ') 
uma predicação de verdade "é verdade que $P$ ". O predicado de verdade permite também generalizar sobre várias proposições ("tudo o que o Papa diz é verdadeiro").

Soames 1999, por outro lado, justifica a defesa do esquema (T) argumentando que ensinamos o significado do predicado "verdade" às crianças dando exemplos do esquema $(\mathrm{T})$. A correcção de $(\mathrm{T})$ é central à noção de verdade porque, segundo Soames, "it incorporates a linguistic rule essential to understand the truth-predicate. Conveying the meaning of the truth-predicate in English involves conveying the acceptability of all instances of $(\mathrm{T})$. Anyone competently employing the predicate cannot reject any such instance". (Soames, 1999, p. 51)

$\mathrm{O}$ deflacionismo é atraente, em grande medida, devido à aparente simplicidade e ao carácter intuitivo dos esquemas de equivalência que exemplificam a teoria. Além do mais, parece dispensar grandes compromissos epistémicos ou metafísicos para explicar a noção de verdade. Mas o deflacionismo também tem sido alvo de bastantes críticas. ${ }^{3} \mathrm{O}$ problema que irei abordar aqui é o de saber se o deflacionismo é compatível com a suposição da existência de contra-exemplos ao princípio de bivalência.

\subsection{O princípio de bivalência e a motivação para o rejeitar}

A bivalência não estabelece que absolutamente tudo é verdadeiro ou falso. A bivalência dirá, isso sim, de um portador de valores de verdade $\mathrm{X}$ à nossa escolha, que X é verdadeiro ou falso. Por outras palavras, aquilo que pode ser um contra-exemplo ao princípio de bivalência deve ser o mesmo tipo de coisa que prevemos ser avaliável como verdadeira ou falsa.

Para simplicidade do argumento, adoptemos (T) e (F) como os esquemas preferidos para a verdade e falsidade. Convém ter em mente que (T) e (F) simplificam demasiado as coisas. Nem todas as frases declarativas são automaticamente avaliáveis como verdadeiras ou falsas; em particular, deve levar-se em consideração o contexto em que as frases são proferidas para determinar o que é dito, ou que proposição é expressa. Vamos supor que no lugar de ' $P$ ' só podemos ter frases que expressem proposições/digam que algo é o caso. O princípio de bivalência deve ser formulado de forma a corresponder a $(\mathrm{T})$ e a $(\mathrm{F})$ :

(B) ' $P$ ' é verdadeira ou ' $P$ ' é falsa.

3 Uma das críticas que lhe são apontadas é a de que não acomoda adequadamente a intuição de que as verdades correspondem, de alguma forma, à realidade. Outra crítica comum é a de que o deflacionismo não é compatível com a semântica vero-condicional. Ver, por exemplo, Dummett 1959, 1991 cap. 3 e 1999, Davidson 1967 e 1996. Para mais críticas ao deflacionismo, ver Wright 1992 cap. 1 e 1999, p. 209 e sqq. 
Assim, um contra-exemplo a (B) será uma frase que diga que algo é o caso, mas que não seja verdadeira nem falsa, isto é:

(Neg-B): Não é o caso que (' $P$ ' é verdadeira ou ' $P$ ' é falsa).

Por que devemos preocupar-nos em saber se (B) é correcto, ou se existem contra-exemplos?

Por um lado, parece manifesto que presumimos que aquilo que dizemos, que pensamos e em que acreditamos é bivalente - que, se não é verdadeiro, então é falso - e isso tem efeitos na forma como pensamos. Contudo, a suposição de que aquilo que dizemos e pensamos é bivalente confronta-se com dificuldades consideráveis, uma vez que deparamos com muitos casos que, aparentemente, não são avaliáveis de uma forma ou de outra quanto ao seu valor de verdade.

Segundo algumas pessoas, como MacFarlane 2003, afirmações contingentes sobre o futuro não têm, no presente, qualquer valor de verdade. Frege 1892 afirmava que frases com ocorrências de nomes próprios/termos singulares vazios exprimem pensamentos que, contudo, não são verdadeiros nem falsos. Strawson 1952 encarava as falhas pressuposicionais como causas de falhas de valores de verdade. Outros ainda, como por exemplo Scott Soames 1999, vêem no paradoxo do mentiroso e na vagueza boas razões para rejeitar a bivalência. Alguns defensores do contextualismo radical, como Charles Travis 1998, 2000, consideram que é contigente que (a maioria de) as nossas afirmações tenham, de todo, valores de verdade.

Fornecem estes casos contra-exemplos genuínos à bivalência? Esta questão é demasiado vasta para ser resolvida neste ensaio. O que podemos fazer é averiguar se a suposição de que há contra-exemplos genuínos à bivalência é compatível com o deflacionismo, e mais concretamente com os esquemas $(\mathrm{T})$ e $(\mathrm{F})$.

\subsection{A incompatibilidade entre o deflacionismo e (Neg-B)}

Suponhamos que o deflacionista tem razão pelo menos no seguinte: os esquemas para a verdade e para a falsidade, $(\mathrm{T})$ e $(\mathrm{F})$, são correctos. Todas as instâncias de $(\mathrm{T})$ e de (F) são verdadeiras, a aceitação dos casos particulares de $(\mathrm{T})$ e (F) é essencial para compreender o que é a verdade e a falsidade, e nenhum caso dos esquemas deve ser rejeitado.

A suposição de que há contra-exemplos a (B) confronta-se com um argumento, simples mas muito poderoso, que mostra que a suposição de (Neg-B) é absurda. Existem várias versões do argumento. Uma delas é avançada precisamente por Horwich 1998 (1990), pp. 76-77, como razão para rejeitar a tese de que existem falhas de valores de verdade (portanto, 
há pelo menos um problema que o deflacionismo de Paul Horwich não tem de enfrentar). Outras versões do mesmo argumento são avançadas por Dummett 1991, pp. 64-65, e Williamson 1992, que argumentam contra a aceitação de um esquema (T) à la Tarski enquanto se afirma que há frases que não são verdadeiras nem falsas; por Williamson 1994, p. 188 contra a suposição de que há elocuções que dizem algo é o caso que não são verdadeiras nem falsas; por Travis 1994, p. 171, que argumenta que não podem existir pensamentos sem valor de verdade. As variações no argumento dizem principalmente respeito à escolha de portadores de valores de verdade e às respectivas formulações de esquemas para a verdade ou falsidade. Dado que Williamson usa explicitamente o argumento em defesa do princípio de bivalência, referır-me-ei a ele como 'o argumento de Williamson'.

Se supusermos que Neg-B, isto é, não é o caso que (' $P$ ' é verdadeira ou ' $P$ ' é falsa), obtemos o seguinte:

1. Não (' $P$ ' é verdadeira ou ' $P$ ' é falsa) suposição

2. Não (P ou não $P$ )

$1,(\mathrm{~T})$ e $(\mathrm{F})$

3. Não $P$ e não não $P$

2, De Morgan

O segundo conjunto em (3) contradiz o primeiro. Portanto, devemos negar a suposição em (1). Não precisamos de eliminar a negação dupla em (3) para que o resultado absurdo se siga. O passo crucial é, claramente, o de (1) para (2), em que (T) e (F) são usados para substituir o lado esquerdo pelo lado direito dos bicondicionais. A aplicação de De Morgan no passo de (2) para (3) não é controversa (note-se que o argumento também é válido intuicionisticamente). Estamos a supor que ' $P$ ' é uma frase que conta como portador legítimo de valores de verdade (seja isso o que for: exprimir uma proposição, dizer que algo é o caso, ter condições de verdade precisas, etc.)

Este argumento pode parecer demasiado forte a algumas pessoas. $\mathrm{Na}$ realidade, a reacção daqueles que rejeitam a bivalência perante este argumento é semelhante à reacção de muitas pessoas perante o argumento ontológico para a existência de Deus. Afinal, ambos são argumentos simples e poderosos, com consequências, para muitos, inaceitáveis. $\mathrm{O}$ argumento é particularmente problemático para os deflacionistas que não se sentem inclinados a defender a bivalência. Como pode o significado do predicado de verdade ser dado nos casos particulares do esquema $(\mathrm{T})$, se alguns dos casos aparentemente legítimos do esquema conduzem a contradições? Os deflacionistas que querem rejeitar a bivalência têm uma necessidade premente de desarmar o argumento de Williamson, sem abdicar daquilo que é essencial ao deflacionismo. 


\section{Tentativas fracassadas}

Para preservar $(\mathrm{T})$ e $(\mathrm{F})$, e admitir contra-exemplos à bivalência, o deflacionista pode/tem de fazer pelo menos algumas das seguintes coisas:

i) Negação: Descobrir ou estipular um sentido de negação alternativo, de tal forma que a negação de que uma frase é verdadeira ou falsa não implique (sempre) uma contradição. Em alternativa, tem de apresentar uma justificação adequada do motivo por que não podemos descrever um putativo contra-exemplo à bivalência como um item que não é verdadeiro nem falso, isto é, tem de justificar o quietismo.

ii) Requisito de prioridade: para que o deflacionista possa defender que todos os casos particulares dos esquemas (T) e (F) são correctos, tem de manter que toda a predicação de verdade " $P$ ' é verdadeira" tem sempre o mesmo estatuto ou valor de verdade que ' $P$ ' (seja ele verdadeiro, falso ou nem verdadeiro nem falso?). E tem também de manter que qualquer predicação de falsidade " " $P$ ' é falsa" inverte o valor de verdade de ' $P$ ', quando esse valor é verdadeiro ou falso, mas preserva o seu estatuto quando ' $P$ ' não é verdadeiro nem falso.

iii) Condicional/bicondicional: a última (e comparativamente menor) variação que é necessária para preservar $(\mathrm{T})$ e (F) é garantir que a equivalência entre os lados direito e esquerdo dos esquemas obtém efectivamente, mesmo que os lados direito e esquerdo respectivos não sejam verdadeiros nem falsos.

Algumas propostas que seguem i), ii) ou iii) são discutidas ou avançadas por várias pessoas, por exemplo, por JC Beall 2002, Field 2001 e 2002, Pelletier e Stainton 2003, Richard 2000 e Soames 1999. Em particular, JC Beall 2002, Richard 2000, e Pelletier e Stainton 2003 consideram a hipótese de rever, de alguma forma, o uso da negação, sem fazer derivar uma contradição, enquanto que Soames 1999 e Field 2002 procuram justificar uma ou outra versão de quietismo.

Em geral, parece presumir-se que o requisito de prioridade é correcto. Kripke 1975 e Soames 1999 avançam defesas explícitas do requisito de prioridade. Finalmente, o facto de a existência de contra-exemplos à bivalência levantar problemas à correcta formulação dos esquemas (T) e (F), nomeadamente na forma como se deve entender o condicional ou o bicondicional, é discutida em particular por Soames 1999, Richard 2000 e Field 2002. Quanto a iii), as modificações na forma como o condicional ou o bicondicional são entendidos só serão úteis na medida em que i) e ii) possam ser defendidos. 


\subsection{A negação}

A negação está intimamente ligada à verdade e à falsidade, e portanto à bivalência. Aqueles que propõem uma revisão do uso da negação em ligação com a rejeição da bivalência podem alegar que há usos da negação que não estão tão intimamente ligados à verdade, à falsidade e à bivalência. Quando dizemos que não é verdadeiro nem falso que $P$, talvez não queiramos dizer que não é verdade que $P$ no sentido em que podemos inferir que $\boldsymbol{P}$ não é o caso; e talvez não queiramos dizer que não é falso que $P$ no sentido em que podemos inferir que não é o caso que não $P$. Mas, se não é isso que queremos dizer, então o que quereremos realmente dizer? Poderá esse uso da negação desarmar o argumento do Williamson ao mesmo tempo que nos permite negar a bivalência?

Existem várias propostas para entender a negação de outra forma. A mais substancial é a de que existem dois sentidos relevantes da negação que podemos distinguir. Há várias propostas na literatura sobre a forma de tratar os dois tipos de negação (e até sobre as designações que devemos atribuir-lhes). Podem ser distinguidos dois tipos de negação chamando-lhes negação forte ('não') e fraca ('na') 4 .

Imagine-se que temos uma frase $P$ que pode ser verdadeira $(\mathrm{V})$, falsa (F) ou falha - e podemos usar '*' para indicar esse estatuto.

A negação dita forte 'não'/ é o sentido de negação que está ligado à falsidade. Uma frase ' $P$ ' é falsa se não é o caso que $P$. Isso não acontece com a negação dita fraca 'na'/ . A negação fraca não significa 'não é o caso que...' e não se supõe que esteja ligada à falsidade (caso contrário, nada é conseguido com a distinção introduzida).

O deflacionista quer, recordemo-nos, que todos os casos particulares dos esquemas para a verdade e falsidade sejam correctos. Sendo assim, pretende preservar a intersubstitutividade entre os lados esquerdos e os lados direitos dos esquemas de equivalências em qualquer contexto. No contexto da negação forte ('não') temos:

- Não (' $P$ ' é verdade) se, e só se, não $P$

- Não (' $P$ ' é falso) se, e só se, não não $P$

No contexto da negação fraca ('na') temos antes:

- Na (' $P$ ' é verdade) se, e só se, na $P$

- Na (' $P$ ' é falso) se, e só se, na não $P$.

4 Podemos usar símbolos em vez de palavras, por exemplo ' ' para a negação fraca e ' $\neg$ ' para a negação forte. 
Assim, se negarmos que ' $P$ ' é verdadeira e que ' $P$ ' é falsa usando 'na' podemos inferir apenas que na $P$ e na não $P$, o que não é nenhuma contradição.

Para que estas equivalências sejam verdadeiras mesmo quando ' $P$ ' é falha $(*)$, as atribuições de verdade ou de falsidade devem ter o mesmo estatuto que $P$, isto é, devem ser, também elas, falhas. Portanto, enquanto o lado direito e esquerdo das equivalências com 'não' são falhas, nas equivalências com 'na', o lado esquerdo e o lado direito são ambos verdadeiros.

Devemos notar que isto quer dizer que não podemos negar que uma afirmação seja bivalente usando 'não' ' ', porque não poderíamos fazer tal afirmação com verdade. Devemos também notar que, para que os esquemas (T) e (F) sejam correctos mesmo quando ambos os seus lados não são bivalentes, devemos tratar o bicondicional na formulação dos esquemas de forma a permitir que um bicondicional da forma 'A sse B' possa ser verdadeiro quando A e B têm o valor */falha.

Tudo parece resolver-se quando consideramos as equivalências esquemáticas com 'na', uma vez que isso parece permitir afirmar com verdade que uma certa frase ou afirmação não é verdadeira nem falsa e parece também manter os esquemas $(\mathrm{T})$ e $(\mathrm{F})$ como correctos.

A dificuldade com que deparamos com o novo tipo de negação prende-se com a dificuldade de explicá-la sem a reduzir à negação forte, e sem a definir circularmente em termos de falha. Não podemos dizer que 'na $P$ ' é verdadeira nas condições indicadas na tabela, e depois querer explicar que uma frase é falha quando não é verdadeira nem falsa. $\mathrm{O}$ problema é que, se o fizéssemos, ou estaríamos a usar a negação forte 'não', e não conseguiríamos progredir de todo, ou estaríamos a usar a negação fraca 'na', o que seria viciosamente circular. Precisamos da noção de negação fraca para descrever as falhas de uma forma não contraditória, mas isso proíbe o uso da noção de falha para definir 'na'. Mesmo que seja possível avançar com diversos sentidos técnicos de negação, não parece haver qualquer motivação independente para usar um sentido ou outro na negação da bivalência. Do meu ponto de vista, a introdução de um novo significado para a negação tem apenas uma justificação, que é evitar a derivação de contradições. E portanto é ad hoc.

Mesmo que o facto de a introdução de 'na' ser ad hoc não seja uma razão persuasiva contra 'na', há outro problema com os usos da negação aqui envolvidos que mencionarei mais à frente.

${ }^{5}$ Uma hipótese seria seguir a sugestão de Beall 2002, que consiste em tratar a negação fraca como primitiva, da mesma forma que a negação forte. Para uma discussão detalhada deste problema e do argumento de Beall, cf. Marques, MS. 


\subsection{Predicados parcialmente definidos e o quietismo}

Recordemo-nos da tabela acima. Nela, a atribuição de 'verdadeira' ou 'falsa' a uma frase ' $P$ ' que é falha resulta numa frase que também é falha. É preciso que assim seja para que os esquemas $(T)$ e $(F)$ sejam verdadeiros mesmo quando ' $P$ ' não tem valor de verdade. Naturalmente, para que $(\mathrm{T})$ e $(\mathrm{F})$ sejam preservados, o bicondicional "...se, e só se..." tem de ser entendido de maneira a ser verdadeiro sempre que ambas as suas condições têm o mesmo estatuto, mesmo que esse estatuto seja uma falha. O deflacionista que quer introduzir falhas precisa portanto de tratar os predicados 'verdadeiro' e 'falso' como predicados que não são aplicáveis em todos os casos - isto é, a preservação de $(\mathrm{T})$ e $(\mathrm{F})$ implica tratar os predicados 'verdadeiro' e 'falso' como predicados que são parcialmente definidos. ${ }^{6}$

Soames 1999 propõe precisamente que se faça uma revisão do bicondicional e se trate a verdade como uma noção parcialmente definida. Segundo Soames, os casos do paradoxo do mentiroso são uma boa motivação para rejeitar a bivalência, e é a suposição de que todas as frases, inclusive o mentiroso, obedecem à bivalência que leva a contradições. Mas Soames admite que negar que uma frase obedece à bivalência leva igualmente a contradições, pelo que propõe um modelo de predicados parcialmente definidos.

Um predicado é parcialmente definido quando é aplicado a itens para os quais não foi definido. Há itens aos quais se aplica claramente, itens aos quais não se aplica claramente, e itens para os quais a sua aplicação ou não-aplicação não está definida. $\mathrm{O}$ modelo parece identificar uma condição que pelo menos alguns predicados podem satisfazer. Segundo Soames, a verdade obedece ao modelo proposto. Os casos do mentiroso, por exemplo, seriam casos para os quais a verdade não está definida.

Soames chama infundamentadas às frases a que eu estou a chamar falhas, mas as frases infundamentadas não devem ser descritas como nem verdadeiras nem falsas, porque isso gera contradições. Essas serão frases que não podemos afirmar, nem negar, nem afirmar que são verdadeiras, nem negar que são verdadeiras, nem afirmar que são falsas, nem negar que são falsas. A única avaliação que podemos fazer sobre elas é que são infundamentadas. ${ }^{7}$

Uma vez que o esquema ( $\mathrm{T})$ pode ser exemplificado com casos como o do mentiroso, haverá pelo menos uma frase ' $Q$ ' tal que ' $Q$ ' é

6 Este ponto é notado por Simons 1992.

${ }^{7}$ Soames usa a noção de uma frase infundamentada tal como usada por Kripke 1975. 
verdadeira sse ' $Q$ ' não é verdadeira, o que não é uma contradição, dada a nova leitura do bicondicional. O modelo de predicados parcialmente definidos proposto estender-se-á ao tratamento de predicados vagos e de outros casos de indeterminação.

Tal como Soames, também Field 2002 advoga a ideia de que não podemos afirmar, sem margem para dúvidas, em que casos é que ' $P$ ' é uma falha, ou é infundamentado, ou se ' $P$ ' tem um valor de verdade ou não.

Esta parece ser a alternativa mais coerente ao dispor do deflacionista. A questão é a de saber se a restrição que consiste em dizer que certos itens têm ou não têm valores de verdade é adequadamente justificável. É muito conveniente que não possamos afirmar que certas frases não são verdadeiras nem falsas, mas que devemos abster-nos de nos pronunciarmos sobre elas. Desta forma evitamos uma auto-contradição. Mas haverá uma boa razão, bem fundamentada, para a restrição? E essa restrição resolverá os problemas que a admissão de falhas pretendia resolver? Ou, mais simplesmente, essa restrição adequar-se-á à motivação que leva algumas pessoas a admitir que há falhas?

Há razões para duvidar de que assim seja. Em primeiro lugar, como é sabido, o mentiroso é vingativo. Isto é, a tentativa de resolver o paradoxo do mentiroso introduzindo a noção de frase infundamentada permite gerar um paradoxo reforçado, (o caso mais simples) "esta frase ou é infundamentada ou não é verdadeira". A introdução de falhas de valores de verdade, ou de um terceiro, ou quarto, ..., ou vigésimo sexto valor de verdade, permitirá novamente gerar um mentiroso reforçado. Em segundo lugar, também é duvidoso que o fenómeno da vagueza seja eliminado pela introdução de falhas entre a verdade e a falsidade, sejam falhas de valores de verdade ou um terceiro, ou quarto, ..., ou vigésimo sexto valor de verdade, porque, como tem sido argumentado por Williamson 1994, Greenough 2003, entre muitos outros, existe o fenómeno de vagueza de ordem superior.

Mas suponhamos que, como sustentam os defensores de que há frases que são falhas ou infundamentadas, esses casos são tão comuns como é alegado. A posição em que nos encontramos com o tipo de quietismo advogado por Soames e Field não é exactamente a mesma que a posição de, por exemplo, um intuicionista. O intuicionista dirá que sabemos que não podemos apontar um caso problemático em particular e dizer que aquele caso não é verdadeiro nem falso. O que nós não sabemos, segundo o intuicionista, é se todos os casos possíveis devem ser verdadeiros ou falsos, porque para isso teríamos de poder provar que a bivalência obtém. Mas, segundo o intuicionista, isso é precisamente o que não podemos fazer.

Com o quietismo do deflacionista, contudo, encontramo-nos numa situação muito mais estranha, que é a de estarmos rodeados de casos que 
podemos apontar (ou indicar gesticulando), que sabemos (alegadamente) que não são verdadeiros nem falsos, mas não podermos descrever esses itens como casos que não são verdadeiros nem falsos. E não podemos fazê-lo porque queremos salvaguardar o esquema $(\mathrm{T})$ dos problemas levantados pela suposição de que há falhas.

Os problemas suscitados por propostas como a de Soames não se restringem à estranheza do quietismo. Outro problema diz respeito à aplicação da noção de predicados parcialmente definidos. Pessoas como Soames defendem, por um lado, que há predicados parcialmente definidos, e, por outro, que a verdade é um desses predicados. Mas os casos que beneficiariam de serem tratados como predicados parcialmente definidos requerem um argumento independente a favor da tese de que são de facto parcialmente definidos. Por exemplo, deveria ser demonstrado de forma independente que os predicados vagos são parcialmente definidos (e que a indeterminação da sua aplicação em casos de fronteira resulta disso mesmo, e não de limitações epistémicas). Deveria ser igualmente demonstrado que outros casos de alegadas falhas resultam deste tipo de fenómeno. Finalmente, deveria haver uma defesa independente da ideia de que a verdade e a falsidade também são noções parcialmente definidas. Mas a única defesa que vislumbro da ideia de que a verdade é parcialmente definida resulta daquilo a que chamo requisito de prioridade.

\subsection{0 requisito de prioridade}

O requisito de prioridade pode ser formulado de maneiras ligeiramente diferentes, mas com o mesmo sentido. Kripke 1975 diz:

"We may say that we are entitled to assert (or deny) of any sentence that it is true precisely under the circumstances when we can assert (deny) the sentence itself" (Kripke, 1975, p. 701)

Soames diz algo semelhante:

" $\ldots$ the procedure to introduce the truth-predicate makes the status of the claim that $S$ is true (or not true) dependent on the prior status of $S$ and ultimately on the status of sentences that do not contain the truth predicate at all." (Soames, 1999, pp. 175-6)

Se o requisito de prioridade é correcto, então justifica o tratamento do predicado de verdade como um predicado parcialmente definido. Os casos para os quais o predicado de verdade não está definido serão aqueles casos de frases que também não podem ser afirmadas ou negadas. Se forem frases simples em que se predica um predicado de um sujeito, 
supõe-se que esse predicado também não está definido a aplicar-se a esse sujeito. Portanto, a falta de fundamentação propaga-se, por assim dizer, à medida que se acrescentam, ou eliminam, atribuições de verdade.

$\mathrm{O}$ requisito de prioridade parece plausível quando aplicado a frases que têm um valor de verdade. Mas o que justifica que o requisito de prioridade seja igualmente aplicado em casos de frases infundamentadas? Em particular, o que favorece, para além do desejo de preservar o esquema (T), a ideia de que uma frase " $P$ ' é verdadeira" é também infundamentada quando ' $P$ ' é infundamentada? À partida, não parece haver mais razões para pensar isso, do que há para pensar que não é verdade que " $P$ ' é verdade", pelo contrário.

Kripke introduz aquilo a que eu estou a chamar requisito de prioridade quando explica como ensinamos a palavra 'verdade' a alguém. $\mathrm{Na}$ realidade, a explicação de Kripke procura captar uma intuição, que é precisamente a mesma intuição (se é que é isso que está em causa) que está por trás do esquema (T). Contudo, Kripke justifica a aplicação do requisito de prioridade a casos problemáticos como o paradoxo do mentiroso, dizendo que é uma "stipulation that he should deny that a sentence is true precisely under the circumstances under which he would deny the sentence itself. In imposing this stipulation, we have imposed a deliberate choice..." (Kripke 1975, p. 702. O sublinhado não está no original). Temos, pois, de ter em mente que, para a teoria que Kripke estava a tentar formular, a aplicação do predicado "verdade" a qualquer frase deve preservar o valor original da frase. Mas, ao mesmo tempo que fornece esta estipulação, Kripke elucida-nos acerca de um ponto que é crucial. Segundo ele,

"Undefined" is not an extra truth-value... If certain sentences express propositions, any tautological truth function of them expresses a proposition. Of course, formulas, even with the form of tautologies, which have components that do not express propositions may have truth functions that do not express propositions either... Mere conventions for handling terms that do not designate numbers should not be called changes in arithmetic; conventions for handling sentences that do not express propositions are not in any philosophically significant sense changes in logic." (Kripke 1975, n. 18, pp. 700-1)

Muito bem. Esta é a posição de Kripke, mas esta posição deixa o verdadeiro defensor de falhas numa situação desconfortável. Se admitirmos que a estipulação do requisito de prioridade para os casos problemáticos mais não é que uma convenção para lidar com frases que podem não expressar proposições, então a intuição a favor do requisito perde toda a sua força. 
O argumento é simples. Podemos descrever inúmeros itens como coisas que não são verdadeiras nem falsas. As cadeiras, as mesas, os chapéus, etc., são coisas desprovidas de valores de verdade. Podemos também descrever inúmeros itens linguísticos como coisas que não são verdadeiras nem falsas. Uma ordem, ou uma pergunta, por exemplo, não parecem ser itens avaliáveis como verdadeiros ou falsos. Em geral, os usos de frases que não pretendem descrever a realidade (digamos assim) também não têm valor de verdade, porque não têm condições de verdade.

Algumas frases que, em princípio, poderiam ter condições de verdade, podem, por qualquer razão, não ter condições de verdade e portanto não "expressar proposições". Este parece ser o caso de frases que contêm termos singulares que não referem por alguma razão (por exemplo, usos de demonstrativos que não identificam nenhum objecto). Não há qualquer razão para não descrever estes itens linguísticos como itens que não são verdadeiros nem falsos. Tal como não têm condições de verdade específicas, também não devemos esperar que exemplifiquem o esquema (T) e portanto nada se segue de negar que são verdadeiros ou que são falsos. Como nada se segue, não se segue qualquer contradição. Portanto, não há nenhuma razão que nos force a seguir a convenção que estipula que o predicado de verdade seja tratado uniformemente mesmo nos casos em que se aplica a itens que não expressam proposições, antes pelo contrário. A descrição "não é verdadeiro nem falso" é, portanto, uma descrição coerente quando aplicada a, pelo menos, algumas coisas. Agora, podemos prosseguir a discussão sobre a justificação do requisito de prioridade, e do esquema $(\mathrm{T})$ em geral.

Quando deparamos com alegados casos de falhas, recorremos ao requisito de prioridade para defender $(\mathrm{T})$ e $(\mathrm{F})$ da possível falsificação pelos casos de falhas. Mas a plausibilidade inicial do requisito de prioridade é idêntica à plausibilidade do esquema. Na realidade, o requisito de prioridade mais não é que uma expressão mais informal da ideia captada em (T). Portanto, apelar ao requisito de prioridade não serve como defesa do esquema (T) em caso de dificuldade.

Contra o quietismo, penso que, se há casos genuínos de falhas, então deve ser verdade dizer que há casos genuínos que não são verdadeiros nem falsos, tal como é verdade descrever certas superfícies coloridas como nem pretas nem brancas, dado que há muitas outras tonalidades. E, se assim é, então não é o caso que " $P$ ' é verdadeira"/ " $P$ ' é falsa" seja falha quando ' $P$ ' é falha. Pelo contrário, não é o caso que ' $P$ ' é verdade e também não é caso que ' $P$ ' é falsa quando ' $P$ ' é falha, ou infundamentada. ${ }^{8}$

Quando dizemos que um certo tom não é branco nem preto, quere-

8 Esta mesma intuição (como Kripke lhe chamava) tinha sido já defendida por Dummett em. 1959, pp. 4-5. 
mos realmente dizer que não é de uma cor ou da outra. Da mesma forma, aquele que pretende negar a bivalência fornecendo contra-exemplos quer dizer "não é verdadeiro nem falso" Ora, se podemos de facto dizer que “" $P$ ' é verdadeira" é falsa quando ' $P$ ' não tem um valor de verdade, então o uso correcto da negação usado na negação da bivalência deve ser a negação forte, 'não', que comuta com a falsidade. Portanto, se uma pessoa quiser negar a bivalência de forma coerente, tem de rejeitar, de uma forma ou de outra, os esquemas $(\mathrm{T})$ e $(\mathrm{F})$, ou fazendo uma revisão, ou uma restrição substancial aos 'esquemas, ou simplesmente abandonando-os. De qualquer maneira, o deflacionista não pode fazê-lo, sem abandonar a tese de que a aceitação dos esquemas é essencial à verdade. E portanto, o deflacionista não pode negar coerentemente a bivalência.

\section{Comentários finais}

Deixem-me concluir com alguns comentários acerca da minha posição sobre este problema. Por um lado, não me sinto minimamente atraída pela ideia de que há falhas de valores de verdade (ou qualquer outro tipo de contra-exemplo à bivalência) e tenho muitas dúvidas sobre a utilidade da ideia de introduzir um terceiro estatuto entre a verdade e a falsidade. Neste aspecto, acompanho Williamson 1994 e Glanzberg 2003, por exemplo. Dummett 1978 argumenta que a base da aplicação das noções de verdade e falsidade a asserções é a ideia de que um falante está certo ou errado ao fazer uma asserção. A ideia de um terceiro estatuto interpõe uma terceira possibilidade para as afirmações: ao fazer uma afirmação, um falante pode nem estar certo nem errado na afirmação que faz. Mas, ao contrário por exemplo das apostas, as asserções não parecem deixar espaço para uma tal falha entre estar certo ou estar errado.

Uma dúvida que permanece é também a da utilidade real de admitir que os casos problemáticos que mencionei no início são contra-exemplos à bivalência. Essa admissão requer explicações alternativas, que em muitos casos, como o do paradoxo do mentiroso ou o da vagueza, continuam a defrontar-se, em geral, com problemas.

Parece-me principalmente que só devemos iniciar o percurso de rejeitar a bivalência, seguindo um caminho inseguro, incerto e pouco claro, se não houver outro percurso melhor a percorrer. Isto é (falando de forma não metafórica), só devemos rejeitar a bivalência, e com ela o esquema (T), se não houver mais nenhuma explicação razoável disponível para os casos problemáticos. Mas estamos provavelmente numa encruzilhada, em que cada saída parece quase tão pouco atraente como as restantes. Por mim, encontro alguma firmeza na ideia de que a verdade é, cumo Aristóteles terá dito, "dizer que o que é é, e que o que não é não é”. 
Infelizmente, isto não é um argumento independente a favor da ideia de que o esquema $(\mathrm{T})$ é essencial à noção de verdade, e portanto não é uma defesa conclusiva da incoerência de negar a bivalência. Espero, contudo, ter defendido de forma convincente que manter que o esquema (T) é essencial à verdade é incoerente com a rejeição da bivalência.

\section{Referências}

Andjelković, M. and Williamson, T. (2000). Truth, Falsity and Borderline Cases. Philosophical Topics 28, 211-44.

Aristóteles, Metafísica

Beall, JC. (2001). A neglected deflationist approach to the liar. Analysis 61, 126-9.

(2002). Deflationism and Gaps: untying 'not's in the debate. Analysis 62, 299-304.

Davidson, D. (1967). Truth and Meaning. Synthese 17, 304-23.

(1996). The folly of trying to define truth. Journal of Philosophy 93, 263-78.

Dummett, M. (1959). Truth. In Truth and Other Enigmas. London: Duckworth, $1-28$.

(1978). Truth and Other Enigmas. London: Duckworth.

(1991). The Logical Basis of Metaphysics. London: Duckworth.

Field, H. (2001). Truth and the Absence of Fact. Oxford: Clarendon Press.

(2002). Saving the Truth Schema from Paradox. Journal of Philosophical Logic 31, 1-27.

Frege (1892). On Sense and Meaning. In P. Geach and M. Black (eds.) Translations from the Philosophical Writings of Gottlob Frege. (3 ${ }^{\text {rd }}$ Edition), Oxford UK and Cambridge USA: Basil Blackwell, 56-78.

Glanzberg, M. Presuppositions, Truth Values, and Expressing Propositions. in Contextualism in Philosophy: on Epistemology, Language and Truth, G.

Pryer and G. Peter (Eds.) OUP (forthcoming).

Horn, L. (1989). A Natural History of Negation. Cambridge Mass.: MIT Press.

Horwich, P. (1998). Truth. (2 $2^{\text {nd }}$ edition) Oxford: Clarendon Press

Kripke, S. (1975). Outline of a Theory of Truth. Journal of Philosophy 72, 690$-716$.

MacFarlane, J. (2003) Future Contingents and Relative Truth. The Philosophical Quarterly 53 (2003), 321-36.

Marques, T. (2006) How not to deny bivalence. manuscrito (MS).

Pelletier, F., and Stainton, R. On 'the denial of bivalence is absurd', Australasian Journal of Philosophy 81, 369-382.

Richard, M. (2000). On an Argument of Williamson's. Analysis 60, 213-17.

Simons, P. (1992) Vagueness and Ignorance. Supp. Volume of the Aristotelian Society, vol. 66, 162-177.

Strawson, P. (1950). On Referring. Mind 59, 320-44 (1952). Introduction to Logical Theory. London: Methuen. 
Travis, C. (1998). Sublunary Intuitionism. In J. Brandl and P. Sullivan (eds.), New Essays on the Philosophy of Michael Dummett. Grazer Philosophische Studien 55, 169-194.

(2000). Unshadowed Thought. Cambridge, Mass. and London, England: Harvard University Press.

Williamson, T. (1992). Vagueness and Ignorance. Aristotelian Society suppl. vol. $66,145-162$.

(1994). Vagueness. London and New York: Routledge.

Wright, C. (1992). Truth and Objectivity. Cambridge, Mass. and London, England: Harvard University Press.

\begin{abstract}
The simplest and most widely endorsed elucidation of the notions of truth and falsehood is given in Aristotle's dictum: "to say of what is not that it is, and of what is that it is not, is false; while to say of what is that it is, and of what is not that it is not, is true". Nowadays, while some take the dictum as the first statement of truth as correspondence, the dictum may also be seen as a first statement of deflationism. Deflationism holds that the essential about truth is captured in equivalence schemas for truth. Similar schemas are usually put forward for falsity. Can deflationism coherently deny bivalence? I will argue that it cannot since the putative counterexamples to bivalence also falsify the relevant truth-schemas. The attempts made to render the supposition of counterexamples to bivalence compatible with the truth-schemas usually take two steps: in the first place, they try to deal with the way we can reject that a relevant item is bivalent without self-contradiction, and, in the second place, they try to explain how, although there are gaps, the schemas for truth and falsehood are still correct. I will argue that these attempts fail, since they are ad hoc or generally ungrounded. So, either deflationism is inadequate as an account of truth, or there cannot be counterexamples to bivalence. I conclude that it is not only deflationism that faces this dilemma; anyone who defends that some version or other of the truth-schemas is correct faces the same difficulties as the deflationist. This would come as no surprise for Aristotle. His dictum about truth was followed by a statement of bivalence: ".so that he who says of anything that it is, or that it is not, will say either what is true or what is false".
\end{abstract}

